\title{
Effectiveness of a Multidisciplinary Chronic Pain Program for Treatment of Refractory Patients With Complicated Chronic Pain Syndromes
}

\author{
Murray J. McAllister, PsyD, Kathryn E. McKenzie, RN, BS, David M. Schultz, MD, \\ and Mikhail G. Epshteyn, PharmD, MS
}

Background: Interventional pain physicians commonly encounter patients with a treatment refractory "chronic pain syndrome." Such patients have a chronically painful medical disorder that is complicated by a number of psychosocial factors, including psychiatric and substance use disorders, physical deconditioning, dependency upon the healthcare system, and perceived impairments that are out of proportion to objective medical findings.

Objective: The objective of the following study was to determine the effectiveness of a multidisciplinary chronic pain program for adult patients with treatment refractory

Interventional pain physicians frequently encounter patients with a treatment refractory "chronic pain syndrome." Such patients have chronically painful medical disorders that are complicated by a number of psychosocial factors, including premorbid or comorbid psychiatric and substance use disorders, physical deconditioning, dependency upon the healthcare system, and perceived impairments that are out of proportion to objective medical findings. A growing body of empirical evidence indicates that the effectiveness of medical interventions is diminished for patients with such psychosocial complications (1-3). There is

From: Medical Advanced Pain Specialists, Minneapolis, Minnesota

Address correspondence:

Murray J. McAllister, PsyD

Medical Advanced Pain Specialists

2104 Northdale Blvd. NW, Suite 220

Minneapolis, MN 55433

E-mail: mmcallister@painphysicians.com

Disclaimer: There was no external funding in prepa-

ration of this manuscript.

Conflict of Interest: None

Manuscript received on $1 / 7 / 2005$

Revision submitted on $9 / 14 / 2005$

Accepted for publication 9/14/2005 chronic pain syndromes.

Methods: The following sequential, prospective, observational case series presents treatment outcome data on a 4 -week multidisciplinary chronic pain program for adult patients with complex chronic pain syndromes that were refractory to standard pain management. Prior to enrollment in the program, patients had been treated with pain medications, physical therapy, and interventional procedures. Data were collected and analyzed on variables including pain ratings, healthcare utilization, opioid medication use, and perceived physical functioning at program admission and discharge as well as at intervals of 3 months, 6 months and 12 months post-discharge.

Results: Analysis of the data reveal statistically significant improvements in the variables of interest across most time parameters.

Conclusions: Results demonstrate that participation in a chronic pain program is an effective intervention for selected patients with refractory pain.

Keywords: multidisciplinary chronic pain program, chronic pain syndromes, treatment outcome, effectiveness also abundant research showing that psychosocial factors play a role in the high rates of healthcare utilization and disability exhibited by patients with complicated chronic pain syndromes (4-7). Because their pain disorders are complicated by psychosocial factors, their coping skills are also challenged and they tend to be overly reliant on opioid medications and the healthcare system in general. Any clinician is familiar with the highly distressed and impaired pain patient who has a long history of failed medical interventions.

Multidisciplinary chronic pain programs (MCPP) have a long association with the traditional goals of reducing or weaning from opioid medications and improving functioning, such as returning to work; other traditional goals of such programs are to decrease pain and to reduce healthcare utilization in general $(8,9)$. As evidenced by the oft-cited metaanalysis of Flor et al (10), numerous investigators have in the past demonstrated the effectiveness of such programs. However, Flor's meta-analysis was performed on research from various investigations occurring prior to the last decade, a decade that witnessed a notable increase in the use of opioids for chronic non-malignant pain. Few investigators have demonstrated effectiveness of such programs within our contemporary climate of the liberal use of opioids. Rome et al (11) showed that reducing or weaning from opioids within a MCPP continues to be feasible but failed to report on whether, or to what extent, these reductions remained once patients were discharged from the program. Dysvik et al (12) and Lang et al (13) demonstrated the effectiveness of MCPP's in terms of pain reduction and improvements in quality of life variables, such as coping, and days off from work. Jensen et al (14) recently showed that return to work status remained improved three years post discharge from their MCPP. However, reductions or weaning from opioids was not a variable of interest in any of these latter studies. The authors of the study reported here were interested in whether a contemporary multidisciplinary chronic pain program could demonstrate significant reductions in opioid medication use while at the same time improving functioning, reducing pain, and reducing healthcare utilization in general. The following presents outcome data with regard to these 
goals for our MCPP at discharge, and 3-, 6-, and 12-months post-discharge.

\section{Methods}

Participants in this study were 276 adult patients $(\mathrm{N}=276)$ sequentially admitted in a MCPP from October 2000 through July 2004. Of these, 93 (33.7\%) were male and $183(66.3 \%)$ were female Ages ranged from 20 to 74 years, with a mean age of 44.7 years (SD 9.7). Ethnicity and racial make-up were the following: white, non-Hispanic 227 (82.2\%); African-American 5 (1.8\%); Hispanic 3 (1.1\%); Native American 2 (0.7\%); and Asian American 1 (0.4\%); 38 (13.8\%) listed no category. The study sample had a mean educational level of 13.46 years (SD 2.37 years). The MCPP had a $19.9 \%$ dropout rate. No follow-up data were maintained on drop outs.

\section{Admission criteria}

Individuals accepted into the MCPP were 18 years of age or older, had chronic non-malignant pain of at least 6 months duration, and experienced significant occupational impairment as defined by an inability to work more than part time, if at all. Prior to enrollment in the program, patients had exhausted all reasonable medical or interventional treatment options. Most patients exhibited distress and impairments across multiple additional areas, including general activity level, affective status, health habits, substance use, relationships and family life, recreation, and overall productivity.

\section{Program description}

The MCPP outpatient program operates on a daily basis for four hours per day, and lasts four weeks. Each day is structured to consist of at least $50 \mathrm{~min}$ utes of pool therapies, 50 minutes of ei- ther group stretching or strengthening, 50 minutes of group coping skills training, and 50 minutes of relaxation and diaphragmatic breathing training.

Each patient in the study participated in at least one hour of individual counseling per week, and the MCPP's nurse practitioner provided medication management. Significant others or family members were encouraged to participate in at least one day of the program. After completion of the four week program, patients were encouraged to attend an aftercare program that included 3 month's use of the pool for exercising, and an indefinite bi-monthly support group.

The staff consisted of a clinical psychologist, physical therapists and physical therapist assistants, registered nurses, and a certified nurse practitioner. All staff had specialized training and experience in chronic pain management. Their respective roles within the program were as follows: the clinical psychologist provided initial evaluations for the program, psychometric testing and reviews of test results, group coping skills training, and consultation to staff; physical therapy staff provided group stretching and strengthening exercises, therapeutic pool exercises, and limited group-based coping skills training; nursing staff provided group coping skills training, case management, individual counseling, relaxation training, and facilitation of the aftercare support groups; the nurse practitioner provided medication management, and limited group coping skills training. Board certified physician consultation was provided as needed.

\section{Data Collection}

Informed consent was obtained to participate in the program, monitor outcomes, and to present the outcomes.
The MCPP collected data on the independent variables of age, sex, race, bodily location of pain disorder, and psychiatric diagnoses.

The MCPP measured the following dependent variables at admission and discharge, as well as at intervals of 3 months, 6 months, and 12 months post-completion. Pain ratings were obtained using a 6-point Likert scale ( $1=$ none; $6=$ very severe). Healthcare utilization data were derived via patient selfreport. Patients were asked to report the number of healthcare visits for any reason during the month prior to each follow-up period. Depending upon the location of the patient's main pain site, general daily functioning was measured with either the Oswestry Back Disability Questionnaire or the Neck Disability Index (NDI). These instruments are commonly used measures of functioning with well established reliability and validity $(15,16)$. Opioid medication usage was tracked at each follow-up period. To allow for comparisons across time and types of opioids, these data were converted to equianalgesic units, using conversion ratios adapted from Gordon et al (17). At the post-discharge follow-up points, forms were mailed to the patient, with a follow-up call asking about health care visits and opioid medication use.

Analyses of the data were performed on SPSS 11.5 for Windows. A p-value of .05 was chosen to determine statistical significance.

\section{RESULTS}

The number of patients in the study varied across variables because not all measures pertained to all patients. Some patients, for instance, completed the Oswestry and some completed the NDI.
Table 1. Pain sites

\begin{tabular}{|l|c|}
\hline Pain location & $\begin{array}{c}\text { Prevalence } \\
(\mathbf{n}=\mathbf{2 7 6})\end{array}$ \\
\hline Low back pain & $33.6 \%$ \\
\hline Multilevel/multi-site & $20.3 \%$ \\
\hline Fibromyalgia & $15.5 \%$ \\
\hline Neck & $7 \%$ \\
\hline Headache & $5.2 \%$ \\
\hline Others & $18.4 \%$ \\
\hline
\end{tabular}

Table 2. Prevalence of comorbid mental health disorders

\begin{tabular}{|l|l|l|}
\hline \multicolumn{1}{|c|}{ Primary } & \multicolumn{1}{|c|}{ Secondary } & \multicolumn{1}{c|}{ Tertiary } \\
\hline $99.2 \%$ Pain disorder & $41.3 \%$ No diagnosis & $79.9 \%$ No diagnosis \\
\hline $0.4 \%$ No diagnosis & $34.1 \%$ Depression & $\begin{array}{l}5.6 \% \text { Substance abuse/ } \\
\text { dependence disorders }\end{array}$ \\
\hline $\begin{array}{l}\text { 0.4\% Somatization } \\
\text { disorder }\end{array}$ & $\begin{array}{l}5.9 \% \text { Substance abuse/dependence } \\
\text { disorders }\end{array}$ & $4.3 \%$ Depression \\
\hline & $5.8 \%$ Generalized anxiety & $2.9 \%$ Generalized anxiety \\
\hline & $\begin{array}{l}3.6 \% \text { Panic disorder with } \\
\text { agoraphobia }\end{array}$ & $\begin{array}{l}2.2 \% \text { Post-traumatic stress } \\
\text { disorder }\end{array}$ \\
\hline & $3.3 \%$ Post-traumatic stress disorder & \\
\hline
\end{tabular}


Table 3. Short-acting and long acting opioid medication use differences

\begin{tabular}{|c|c|c|c|c|c|c|}
\hline & \multicolumn{3}{|c|}{ Short-acting opioid } & \multicolumn{3}{|c|}{ Long-acting opioid } \\
\hline & Admit & Follow-up & $\begin{array}{l}\mathrm{t} \text {-score/ } \\
\mathrm{p} \text { value }\end{array}$ & Admit & Follow-up & $\begin{array}{l}\text { t-score/ } \\
\text { p value }\end{array}$ \\
\hline $\begin{array}{l}\text { Admit to } \\
\text { Discharge }\end{array}$ & $\begin{array}{c}0.7130 \pm 0.8369 \\
(142)\end{array}$ & $\begin{array}{c}0.3347 \pm 0.5519 \\
(142)\end{array}$ & $\begin{array}{c}7.188 \\
(\mathrm{p}<0.001)\end{array}$ & $\begin{array}{c}3.5416 \pm 3.4536 \\
(113)\end{array}$ & $\begin{array}{c}2.7681 \pm 2.9244 \\
(113)\end{array}$ & $\begin{array}{c}5.064 \\
(\mathrm{p}<0.001)\end{array}$ \\
\hline $\begin{array}{l}\text { Admit to } \\
\text { 3-month }\end{array}$ & $\begin{array}{c}0.7358 \pm 0.8675 \\
(117)\end{array}$ & $\begin{array}{c}0.3427 \pm 0.5436 \\
(117)\end{array}$ & $\begin{array}{c}5.346 \\
(\mathrm{p}<0.001) \\
\end{array}$ & $\begin{array}{c}3.5187 \pm 3.6500 \\
(91)\end{array}$ & $\begin{array}{c}2.4613 \pm 2.9181 \\
(91)\end{array}$ & $\begin{array}{c}4.068 \\
(\mathrm{p}<0.001)\end{array}$ \\
\hline $\begin{array}{l}\text { Admit to } \\
\text { 6-month }\end{array}$ & $\begin{array}{c}0.8037 \pm 0.9360 \\
(93)\end{array}$ & $\begin{array}{c}0.3397 \pm 0.5414 \\
(93)\end{array}$ & $\begin{array}{c}4.601 \\
(\mathrm{p}<0.001)\end{array}$ & $\begin{array}{c}3.6994 \pm 3.9286 \\
(80)\end{array}$ & $\begin{array}{c}2.8351 \pm 2.9864 \\
(80)\end{array}$ & $\begin{array}{c}2.330 \\
(\mathrm{p}<0.05)\end{array}$ \\
\hline $\begin{array}{l}\text { Admit to } \\
\text { 12-month }\end{array}$ & $\begin{array}{c}0.8746 \pm 1.0353 \\
(59)\end{array}$ & $\begin{array}{c}0.5198 \pm 0.9509 \\
(59)\end{array}$ & $\begin{array}{c}2.036 \\
(p<0.05)\end{array}$ & $\begin{array}{c}3.6407 \pm 3.9189 \\
(54)\end{array}$ & $\begin{array}{c}2.9046 \pm 3.2050 \\
(54)\end{array}$ & $\begin{array}{c}1.600 \\
\mathrm{~ns}\end{array}$ \\
\hline
\end{tabular}

Table 4. Mean pain ratings differences

\begin{tabular}{|l|c|c|c|c|}
\hline & N & Admit & Follow-up & $\begin{array}{c}\text { t-score } \\
\text { (p value })\end{array}$ \\
\hline $\begin{array}{l}\text { Admit to } \\
\text { Discharge }\end{array}$ & 200 & $4.97 \pm 0.690$ & $4.43 \pm 0.746$ & $\begin{array}{c}10.037 \\
(\mathrm{p}<0.001)\end{array}$ \\
\hline $\begin{array}{l}\text { Admit to } \\
\text { 3-month }\end{array}$ & 129 & $4.92 \pm 0.657$ & $4.56 \pm 0.838$ & $\begin{array}{c}4.349 \\
(\mathrm{p}<0.001)\end{array}$ \\
\hline $\begin{array}{l}\text { Admit to } \\
\text { 6-month }\end{array}$ & 107 & $4.84 \pm 0.702$ & $4.37 \pm 0.906$ & $\begin{array}{c}5.475 \\
(\mathrm{p}<0.001)\end{array}$ \\
\hline $\begin{array}{l}\text { Admit to } \\
\text { 12-month }\end{array}$ & 78 & $5.01 \pm 0.655$ & $4.53 \pm 0.833$ & $\begin{array}{c}5.598 \\
(\mathrm{p}<0.001)\end{array}$ \\
\hline
\end{tabular}

Within individual variables, sample sizes differed across time parameters because: the study involved a rolling admission; some patients refused further follow-up; others were lost to follow-up.

Table 1 shows the most prevalent bodily locations for chronic pain. By the far the most prevalent - chronic low back pain - was roughly one-third of the sample. Multilevel or multi-site chronic pain, such as having two separate chronic pain disorders affecting different areas of the body, constituted one-fifth of the sample. Fibromyalgia syndrome, chronic neck pain, and chronic headache were the next most common. Other diagnoses, such as neuropathies, complex regional pain syndromes, knee pain, and the like, made up the rest, but none of these diagnostic categories by themselves constituted more than $3 \%$ of the sample. We subsequently collapsed them into one reported category, titled "Other."

Table 2 shows the most prevalent mental health diagnoses. Diagnoses were made by the clinical psychologist in accordance with criteria as specified by the $D i$ agnostic and Statistical Manual, $4^{\text {th }}$ Edition (18). As indicated below, the vast majority met diagnostic criteria for a "Pain Disorder Associated with Both Psychological Features and a General Medical Condition," or what is commonly referred to as "chronic pain syndrome." Most prevalent secondary and tertiary diagnoses were major depression, and the various anxiety and substance abuse disorders. Because no one substance abuse or dependence disorder ranked more than $3 \%$, these were collapsed into a single reported variable of abuse and dependence.

Tables 3-6 show the results of paired sample t-tests for the variables of interest with comparisons between the time parameters of admission and each of the different periods of follow-up. Table 3 shows a significant reduction with regards to short-acting medication use and long-acting opioid medication use at discharge, 3 months, and 6 months, and a non-significant trend towards reduction at one year. Table 4 demonstrates significant reductions in pain across all time parameters. Table 5 indicates statistically significant improvements in functioning through one year as measured by the Oswestry Back Questionnaire. Table 5 also demonstrates a significant reduction in perceived physical disability as measured by the Neck Disability Index only at initial discharge, 3 month and 6 month periods. However, these improvements in functioning fail to continue at 1 year postcompletion. Table 6 exhibits statistically significant reductions in healthcare utilization across all time parameters.

Table 5. Mean Oswestry Back Score and Neck Disability Index Score differences

\begin{tabular}{|c|c|c|c|c|c|c|}
\hline & \multicolumn{3}{|c|}{ Oswestry Back Score } & \multicolumn{3}{|c|}{ Neck Disability Index Score } \\
\hline & Admit & Follow-up & t-score & Admit & Follow-up & t-score \\
\hline $\begin{array}{l}\text { Admit to } \\
\text { Discharge }\end{array}$ & $\begin{array}{c}0.5217 \pm 0.1436 \\
(183)\end{array}$ & $\begin{array}{c}0.4502 \pm 0.1631 \\
(183)\end{array}$ & $\begin{array}{c}8.623 \\
(\mathrm{p}<0.001)\end{array}$ & $\begin{array}{c}0.4996 \pm 0.1476 \\
(146)\end{array}$ & $\begin{array}{c}0.4119 \pm 0.1718 \\
(146)\end{array}$ & $\begin{array}{c}7.422 \\
(p<.001)\end{array}$ \\
\hline $\begin{array}{l}\text { Admit to } \\
\text { 3-month }\end{array}$ & $\begin{array}{c}0.5241 \pm 0.1453 \\
(112)\end{array}$ & $\begin{array}{c}0.4602 \pm 0.1753 \\
(112)\end{array}$ & $\begin{array}{c}4.738 \\
(\mathrm{p}<0.001)\end{array}$ & $\begin{array}{c}0.5036 \pm 0.1466 \\
(92)\end{array}$ & $\begin{array}{c}0.4604 \pm 0.1690 \\
(92)\end{array}$ & $\begin{array}{c}2.903 \\
(\mathrm{p}<.005) \\
\end{array}$ \\
\hline $\begin{array}{l}\text { Admit to } \\
\text { 6-month }\end{array}$ & $\begin{array}{c}0.5038 \pm 0.1423 \\
(93)\end{array}$ & $\begin{array}{c}0.4515 \pm 0.1860 \\
(93)\end{array}$ & $\begin{array}{c}3.284 \\
(\mathrm{p}<0.001)\end{array}$ & $\begin{array}{c}0.4943 \pm 0.1451 \\
(74)\end{array}$ & $\begin{array}{c}0.4550 \pm 0.1757 \\
(74)\end{array}$ & $\begin{array}{c}2.299 \\
(\mathrm{p}<.024)\end{array}$ \\
\hline $\begin{array}{l}\text { Admit to } \\
\text { 12-month }\end{array}$ & $\begin{array}{c}0.5114 \pm 0.1570 \\
(69)\end{array}$ & $\begin{array}{c}0.4480 \pm 0.1805 \\
(69)\end{array}$ & $\begin{array}{c}3.206 \\
(\mathrm{p}<0.002)\end{array}$ & $\begin{array}{c}0.4832 \pm 0.1440 \\
(53)\end{array}$ & $\begin{array}{c}0.4672 \pm 0.1764 \\
(53)\end{array}$ & $\begin{array}{l}.763 \\
\text { (ns) }\end{array}$ \\
\hline
\end{tabular}


Table 6. Mean healthcare utilization differences

\begin{tabular}{|l|c|c|c|c|}
\hline & $\mathbf{N}$ & Admit & Follow-up & $\begin{array}{c}\text { t-score } \\
(\mathbf{p} \text { value })\end{array}$ \\
\hline $\begin{array}{l}\text { Admit to } \\
\text { Discharge }\end{array}$ & 219 & $4.0 \pm 3.60$ & $1.22 \pm 1.84$ & $\begin{array}{c}13.615 \\
(\mathrm{p}<0.001)\end{array}$ \\
\hline $\begin{array}{l}\text { Admit to } \\
\text { 3-month }\end{array}$ & 167 & $3.92 \pm 3.46$ & $2.55 \pm 3.14$ & $\begin{array}{c}4.443 \\
(\mathrm{p}<0.001)\end{array}$ \\
\hline $\begin{array}{l}\text { Admit to } \\
\text { 6-month }\end{array}$ & 142 & $4.32 \pm 3.96$ & $2.46 \pm 2.39$ & $\begin{array}{c}5.826 \\
(\mathrm{p}<0.001)\end{array}$ \\
\hline $\begin{array}{l}\text { Admit to } \\
\text { 12-month }\end{array}$ & 99 & $4.24 \pm 3.90$ & $2.53 \pm 2.37$ & $\begin{array}{c}4.341 \\
(\mathrm{p}<0.001)\end{array}$ \\
\hline
\end{tabular}

\section{Discussion}

As most interventional pain physicians know, patients with complicated chronic pain syndromes are difficult to treat. They report unrelenting pain despite a history of medical interventions and have high rates of psychiatric and substance use comorbidity, heightened perceived disability, and high rates of healthcare utilization. Over the past decade, this population has experienced a significant increase in the liberal use of opioid medications. While past research has consistently shown MCPP's to be an effective treatment approach, there seems a paucity of investigations showing their effectiveness within the present zeitgeist of routinely managing this population of patients with long-term opioids. The authors were interested in whether a contemporary MCPP could demonstrate significant reductions in opioid medication use while at the same time also reduce pain, improve functioning, and reduce healthcare utilization. The preceding data show that participation in a MCPP is an effective therapy.

Patients on average maintained significantly less use of short-acting opioids for at least a year. In terms of long-acting opioid use, patients maintained significant reductions through 6-month follow-up. The reduction was roughly equivalent to an average of 9 less milligrams of methadone per day in comparison to patient regimes when beginning the MCPP. While average reductions continued at 1 year, this trend failed to reach statistical significance.

Participation in the MCPP consistently reduced pain for at least a year following its completion. At admission, on average, patients rated their pain as "severe" whereas at each of the follow-up points through 1 year post-completion, patients rated their pain between "moderate" and "severe." Such a finding is impressive considering the concomitant reductions in opioid use, and generalized reductions in healthcare utilization. Regarding the healthcare utilization data, our findings indicate that patients had on average one and one-half fewer healthcare visits per month, and that these reductions continued at 1 year post-completion. These data are suggestive that participation in a MCPP is also a cost-effective, and likely cost-saving, intervention. As measured by the Oswestry, patients showed significant reductions in perceived impairments at all time parameters. Such a finding indicates that, with regard to low back pain, participation in a chronic pain program improves daily functioning. With the Neck Disability Index, patients reported improved functioning through 6 months post discharge.

\section{Conclusions}

The goals of a MCPP are typically to reduce use of opioid medications, reduce the experience of pain, improve functioning, and reduce healthcare utilization. $\mathrm{Pa}$ tient selection criteria are treatment refractory patients who display a chronic pain syndrome that is complicated by psychosocial factors, such as premorbid or comorbid psychiatric or substance use disorders, heightened perceived impairments, and over-reliance on the healthcare system. The preceding exhibits outcomes for these parameters at admission and discharge, as well as 3-, 6-, and 12month follow-ups. These data show that participation in a MCPP involving behavioral health and physical therapy interventions is an effective treatment for a patient population that is exceptionally difficult to treat.
AUthOR AfFILIATION:

Murray J. McAllister, PsyD

Director, Behavioral Health

Medical Advanced Pain Specialists

2104 Northdale Blvd. NW, Suite 220

Minneapolis, MN 55433

E-mail:

mmcallister@painphysicians.com

Kathryn E. McKenzie, RN, BS

Director, Chronic Pain Program

Medical Advanced Pain Specialists

2104 Northdale Blvd. NW, Suite 220

Minneapolis, MN 55433

David M. Schultz, MD

Assistant Professor of Anesthesiology

University of Minnesota

and Medical Director,

Medical Advanced Pain Specialists

2104 Northdale Blvd. NW, Suite 220

Minneapolis, MN 55433

Mikhail G. Epshteyn, PharmD, MS

Director, Pharmacy

Medical Advanced Pain Specialists

2104 Northdale Blvd. NW, Suite 220

Minneapolis, MN 55433

\section{RefERENCES}

1. Block, A. R. Presurgical psychological screening in chronic pain syndromes: $A$ guide for the behavioral health practitioner. Lawrence Erlbaum Associates, Mahwah, NJ: 1996.

2. Schofferman J, Anderson D, Hines R, Smith $\mathrm{G}$, White A. Childhood psychological trauma correlates with unsuccessful lumbar spine surgery. Spine 1992; 17:138-144.

3. Schofferman J, Anderson D, Hines R, Smith G, Keane G. Childhood psychological trauma and chronic refractory low-back pain. Clin J Pain 1993; 9:260-265.

4. Gatchel RJ. Comorbidity of chronic pain and mental health disorders: The biopsychosocial perspective. American Psychologist 2004; 59:795-805.

5. Waddell G, Newton M, Henderson I, Somerville D, Main CJ. A fear-avoidance beliefs questionnaire (FABQ) and the role of fear-avoidance beliefs in chronic low back pain and disability. Pain 1993; 52: 157-168.

6. Vlaeyen JWS, Linton SJ. Fear-avoidance and its consequences in chronic musculoskeletal pain: A state of the art. Pain 2000; 85:317-332. 
7. Engel CC, Von Korff M, Katon WJ. Back pain in primary care: Predictors of high healthcare costs. Pain 1996; 65:197-204.

8. Loeser JD. The role of chronic pain clinics in managing back pain. In Frymoyer JW (ed). The adult spine: Principles and practice. Raven Press, New York, 1991, pp 221229.

9. Turk D C. Clinical effectiveness and costeffectiveness of treatments for patients with chronic pain. Clin J Pain 2002; 18: 355-365.

10. Flor H, Fydrich T, Turk D. Efficacy of multidisciplinary pain treatment centers: A meta-analytic review. Pain 1992; 49:221230.

11. Rome JD, Townsend CO, Bruce BK, Sletten CD, Luedtke CA, Hodgson JE. Chronic non- cancer pain rehabilitation with opioid withdrawal: Comparison of treatment outcomes based on opioid use status at admission. Mayo Clin Proc 2004; 79:759768.

12. Dysvik E, Vinsnes AG, Eikeland OJ. The effectiveness of a multidisciplinary pain management programme managing chronic pain. International Journal of Nursing Practice 2004; 10:224-234.

13. Lang K, Liebig K, Kastner S, Neundorfer B, Heuschmann P. Multidisciplinary rehabilitation versus usual care for chronic low back pain in the community: Effects on quality of life. The Spine Journal 2003; 3: 270-276.

14. Jensen IB, Bergstrom $G$, Ljungquist $T$, Bodin L. A 3-year follow-up of a multidisci- plinary rehabilitation programme for back and neck pain. Pain 2005; 115:273-283.

15. Fairbank JC, Mbaot JC, Davies JB, O’Brien, JP. The Oswestry low back disability questionnaire. Physiotherapy 1980; 66:271273.

16. Vernon $\mathrm{H}$, Moir $M$. The neck disability index: A study of reliability and validity. I Manip Physiol Ther 1991; 14:409-415.

17. Gordon DB, Stevenson KK, Griffie J, Muchka S, Rapp C, Ford-Roberts K. Opioid Equianalgesic Calculations. J Palliative Med 1999; 2:209-218.

18. American Psychiatric Association. Diagnostic and Statistical Manual, 4th edition. American Psychiatric Association, Washington, DC: 1994. 